\title{
Kajian Jumlah Armada Angkutan Kota Malang Berdasarkan SPM 2015 ( Studi Kasus: Trayek AH, LDH, ADL )
}

\author{
Filki Suri Widyatami, Achmad Dzulfiqar Alfiansyah, Harnen Sulistio, Achmad Wicaksono \\ Jurusan Teknik Sipil Fakultas Teknik Universitas Brawijaya \\ Jl. MT. Haryono No. 167 Malang, 65145, Jawa Timur \\ Email: filkisuri94@gmail.com \& achmad959422@gmail.com
}

\begin{abstract}
Abstrak
Angkutan kota di Malang sudah ada sejak ada sejak tahun 1980an. Angkutan kota saat itu sebagai andalan masyarakat kota Malang untuk berpindah dari satu tempat ke tempat lainnya. Tetapi semanjak mudahnya membeli kendaraan pribadi dan murahnya harga kendaraan pribadi yang ada di pasaran membuat angkutan kota Malang jarang peminat. Masyarakat Kota Malang lebih memilih naik kendaraan pribadi untuk berpindah dari satu tempat ke tempat lainnya. Hal tersebut menyebabkan jumlah armada angkutan kota Malang saat ini tidak efisien.Perlu dilakukan kajian mengenai jumlah armada yang ideal.Terdapat dua analisis pada kajian ini, analisis pertama untuk mengetahui tingkat pelayanan angkutan umum Kota Malang berdasarkan SPM 2015 menggunakan metode Importance Performance Analysis (IPA). Analisis kedua untuk mengetahui jumlah armada optimum menggunakan dua metode yaitu Load Factor dan Break Even Point. Untuk analisis pelayanan didapatkan jumlah responden sebanyak 68 reponden untuk tiap trayek, dan penyebaran kuisioner dilakukan di dalam angkutan dan diluar angkutan. Hasil kajian menunjukkan kinerja pelayanan angkutan kota Malang trayek AH, LDH, dan ADL berdasarkan SPM tahun 2015 di dapatkan ada beberapa aspek yang berada di prioritas utama dan kinerja pelayanan angkutan umum yang rendah yaitu Sopir mengangkut penumpang tidak melebihi kapasitas, larangan merokok bagi penumpang dan sopir dalam kendaraan, Adanya prioritas untuk penyandang cacat, manusia usia lanjut, anak-anak, dan wanita hamil, dan Adanya informasi tentang trayek yang dilalui. Pada analisis jumlah armada didapatkan jumlah armada dengan metode Load Factor sebesar 132 armada untuk trayek AH, 85 armada untuk trayek LDH dan 75 armada untuk trayek ADL. Sedangkan jumlah armada dengan metode Break Even Point sebesar 237 armada untuk trayek AH, 130 armada untuk trayek LDH, dan 105 armada untuk trayek ADL. Yang lebih efisien dari penentuan jumlah armada diantara metode Load Factor dan Break Even Point adalah dengan Load Factor. Untuk optimasi jumlah armada angkutan umum Kota Malang dapat menggunakan cara membagi kerja jumlah armada dengan beberapa shift kerja.
\end{abstract}

Kata Kunci : Angkutan, Jumlah Armada, Kinerja Operasi, Metode Break Even Point, Metode Importance Performance Analysis.

\section{Pendahuluan}

Kota Malang merupakan kota yang berada di Provinsi Jawa Timur, merupakan kota terbesar kedua setelah Surabaya dengan luas 110,06 km2 dan jumlah penduduk 873716 jiwa. Kota Malang merupakan kota yang dikenal dengan destinasi pariwisata alamnya. Hal tersebut membuat kota Malang banyak dikunjungi pendatang baik dari dalam provinsi, luar provinsi dan luar pulau. Selain dikenal sebagai kota wisata, kota Malang juga dapat dikenal sebagai kota pelajar dengan banyaknya perguruan tinggi negeri dan swasta yang didirikan di kota Malang. Hal tersebut menyebabkan pertambahan penduduk yang berasal dari kota kota lain seluruh Indonesia. Dengan kondisi kependudukan yang padat ditambah persebaran kawasan industri dan pendidikan yang tidak terpusat membuat kondisi lalu lintas di kota Malang banyak mengalami kemacetan.

Angkutan kota di Malang sudah ada sejak ada sejak tahun 1980an. Angkutan kota saat itu sebagai andalan masyarakat kota Malang untuk berpindah dari satu tempat ke tempat lainnya. Tetapi semanjak mudahnya membeli kendaraan pribadi dan murahnya harga kendaraan pribadi yang ada di pasaran membuat angkutan kota Malang jarang peminat. Masyarakat Kota Malang lebih memilih naik kendaraan pribadi untuk berpindah dari satu tempat ke tempat lainnya. Banyaknya masyarakat yang berpindah dari angkutan kota ke kendaraan pribadi membuat beberapa trayek terpaksa tidak beroperasi lagi dan membuat jumlah armada yang tidak efisien. Oleh karena itu perlu dilakukan kajian tentang jumlah armada berdasarkan standar pelayanan untuk megetahui kinerja pelayanan dan jumlah armada angkutan kota yang optimal di Kota Malang. Penelitian ini bertujuan untuk:

1. Mengetahui pelayanan angkutan kota Malang trayek AH, LDH, dan ADL berdasarkan Standart Pelayanan Minimum (SPM) tahun 2015 dengan metode Importance Performance Analysis (IPA)

2. Mengetahui jumlah armada yang efisien untuk trayek AH, LDH, dan ADL sesuai dengan kebutuhan, apabila di analisis dengan menggunakan metode Load Factor dan Break Even Point

3. Mengetahui metode yang paling efisien diantara metode Load Factor dan Break Even Point

4. Mengetahui cara mengoptimasi jumlah armada angkutan perkotaan.

\footnotetext{
* Corresponding author. Tel.: +62

E-mail address: filkisuri94@gmail.com,achmad959422@gmail.com
} 


\section{Tinjauan Pustaka}

\subsection{Kinerja Pelayanan Angkutan Perkotaan berdasarkan SPM 2015}

Standar pelayanan minimal (SPM) angkutan perkotaan merupakan standar yang harus dipenuhi setiap angkutan perkotaan pada saat beroperasi. Bukan hanya angkutan perkotaan yaang harus memenuhi SPM tersebut tetapi semua angkutan umum, baik yang melayani antar negara, antar kota antar provinsi, maupun antar kota dalam provinsi. SPM angkutan perkotaan dikeluarkan oleh Menteri Perhubungan. SPM ditujukan untuk menjamin pelayanan terhadap penumpang dalam menggunakan angkutan perkotaan. Secara garis besar SPM dibagi menjadi enam aspek yaitu keamanan, keselamaaturantan, kenyamanan, Keterjangkauan, kesetaraan dan kete. Dalam kenam aspek tersebut terdapat beberapa poin yang perlu dipenuhi bagi setiap penyedia jasa angkutan perkotaan. setiap penyedia jasa angkutan perkotaan.

\subsection{Biaya Operasional Kendaraan ( BOK )}

Biaya operasi kendaraan adalah total biaya yang dikeluarkan oleh pengendara dalam menggunakan moda. Biaya operasi dan nilai waktu merupakan dua komponen penting dalam menentukan nilai biaya gabungan. Biaya gabungan adalah kombinasi linear antara jarak dan waktu, dan digunakan untuk menentukan pemilihan rute (Tamin, 2000:96). Konsep biaya gabungan terdiri dari tiga komponen yaitu jarak, biaya dan waktu.

Berdasarkan Dirjen Perhubungan Darat tahun 2002, biaya operasional angkatan darat terbagi atas biaya langsung dan tidak langsung. Biaya langsung terdiri dari penyusutan kendaraan produktif, bunga modal kendaraan produktif, awak bus, Bahan Bakar Minyak (BBM), ban, servis kecil, servis besar, pemeriksaan, penambahan oli, suku cadang dan bodi, cuci, retribusi terminal, STNK/pajak kendaraan, kir, dan asuransi. Sedangkan biaya tidak langsung terdiri dari biaya pegawai selain awak kendaraan dan pengelolaan.

\subsection{Penentuan Jumlah Armada}

Metode Faktor Muat ( Load Factor )

Faktor muat (load factor) merupakan perbandingan antara kapasitas terpakai dengan kapasitas tersedia yang bisa dinyatakan dalam persen $(\%)$, atau perbandingan antara jumlah penumpang dengan jumlah kapsitas tempat duduk dan dinyatakan dalam persen (\%). Sedangkan kapaistas kendaraan adalah daya muat penumpang pada setiap kendaraan angkutan umum (LPITB, 1997).

Adapun rumus untuk menghitung Faktor Muat (load factor), seperti :

Faktor Muat (Load Factor) $\quad=\frac{\Sigma \text { penumpang }}{\Sigma \text { kapasitas tempat duduk }} \times 100 \%$

Komponen perhitungan pada metode ini menurut Direktorat Jendral Perhubungan Darat (2002) adalah kapasitas kendaraan, waktu sirkulasi, waktu henti kendaraan diterminal dan waktu antara. Untuk kapasitas kendaraan direktorat jendral perhubungan darat mempunyai standart tersendiri berdasarkan jenis jenis angkutan yang digunakan.

Untuk waktu sikulus Direktorat Jendral Perhubungan darat menetapkan waktu henti kendaraan di asal dan tujuan $\left(\mathrm{T}_{\mathrm{TA}}+\right.$ $\mathrm{T}_{\mathrm{TB}}$ ) ditetapkan sebesar $10 \%$ dari waktu perjalanan antar A dan B. Dan kecepatan kendaraan rata-rata $20 \mathrm{~km}$ perjam dengan deviasi waktu sebesar 5\% dari waktu perjalanan. Dan dirumuskan sebagai berikut:

$\mathrm{CT}_{\mathrm{ABA}}=\left(\mathrm{T}_{\mathrm{AB}}+\mathrm{T}_{\mathrm{BA}}\right)+\left(\sigma_{\mathrm{AB}}+\sigma_{\mathrm{BA}}\right)+\left(\mathrm{T}_{\mathrm{TA}}+\mathrm{T}_{\mathrm{TB}}\right)$

dimana:

$\mathrm{CT}_{\mathrm{ABA}}=$ Waktu sirkulasi dari A ke B kembali lagi ke A

$\mathrm{T}_{\mathrm{AB}}=$ Waktu perjalanan rata-rata dari $\mathrm{A}$ ke $\mathrm{B}$

$\mathrm{T}_{\mathrm{BA}}=$ Waktu perjalanan rata-rata dari $\mathrm{B}$ ke $\mathrm{A}$

$\sigma_{\mathrm{AB}}=$ Deviasi waktu perjalanan dari A ke B

* Corresponding author. Tel.: +62

E-mail address: muhisran@yahoo.com 
$\sigma_{\mathrm{BA}}=$ Deviasi waktu perjalanan dari B ke A

$\mathrm{T}_{\mathrm{TA}}=$ Waktu henti kendaraan di $\mathrm{A}$

$\mathrm{T}_{\mathrm{TB}} \quad=$ Waktu henti kendaraan di $\mathrm{B}$

Untuk waktu antara menurut Direktorat Jendaral Perhubungan Darat dirumuskan sebagai berikut:

$$
\mathrm{H}=\frac{60 \times \mathrm{C} \times \mathrm{Lf}}{\mathrm{P}}
$$

dimana:

$\begin{array}{ll}\mathrm{H} & =\text { Waktu antara (menit) } \\ \mathrm{H} \text { ideal } & =5-10 \text { menit } \\ \mathrm{H} \text { puncak } & =2-5 \text { menit } \\ \mathrm{P} & =\text { Jumlah Penumpang perjam pada seksi terpadat } \\ \mathrm{C} & =\text { Kapasitas Kendaraan } \\ \text { Lf } & =\text { faktor muat }\end{array}$

Sehingga jumlah armada perwaktu sirkulasi menurut Direktorat Jendral perhubungan darat dirumuskan sebagai berikut:

$$
\mathrm{K}=\frac{\mathrm{Ct}}{\mathrm{H} \times \mathrm{fA}}
$$

dimana:

$$
\begin{array}{ll}
\mathrm{K} & \text { = Jumlah Kendaraan } \\
\mathrm{Ct} & =\text { Waktu sirkulasi (menit) } \\
\mathrm{H} & =\text { Waktu antara } \\
\mathrm{fA} & \text { = faktor ketersediaan kendaraan }(100 \%)
\end{array}
$$

\section{Metode Break Even Point ( BEP)}

Break even point (BEP) merupakan metode analisis untuk mengetahui berapa jumlah barang yang harus dijual agar suatu perusahaan tersebut mengalami keuntungan. Jika nilai BEP $=0$ menandakan suatu perusahaan tersebut tidak mengalami kerugian dan tidak mengalami keuntungan. Rumus BEP dapat dirumuskan sebagai berikut:

$\mathrm{BEP}=\frac{\text { Total Fixed Cost }}{\text { Harga perunit-variabel cost perunit }}$

Untuk menghitung jumlah armada, pertama kita harus mencari load faktor menggunakan rumus BEP, dan dirumuskan sebagai berikut:

$$
\mathrm{LF}_{\mathrm{BEP}}=\frac{\text { BOK }}{\text { Pendapatan perhari }} \times \mathrm{LF}
$$

dimana:

$\mathrm{LF}_{\mathrm{BEP}}=$ Load Factor berdasarkan nilai BEP

BOK = Biaya Operasional Kendaraan angkutan umum

\footnotetext{
* Corresponding author. Tel.: +62

E-mail address: muhisran@yahoo.com
} 
LF = Load Factor

Maka jumlah armada dapat dihitung sebagai berikut:

$$
\mathrm{KT}=\frac{\mathrm{LF}}{\mathrm{LF}_{\mathrm{BEP}}} \times \mathrm{KO}
$$

Dimana:

KT = jumlah armada yang dibutuhkan

LF = Load Factor (Faktor Muat)

$\mathrm{LF}_{\mathrm{BEP}}=$ Load Factor berdasarkan nilai BEP

$\mathrm{KO}=$ Jumlah armada yang beroperasi saat ini

\subsection{Importance Analysis Performance (IPA)}

Metode ini mempunyai fungsi utama untuk menampilkan informasi berkaitan dengan faktor-faktor pelayanan yang menurut konsumen sangat mempengaruhi kepuasan dan loyalitas mereka, dan faktor-faktor pelayanan yang menurut konsumen perlu ditingkatkan karena kondisi saat ini belum memuaskan. Penerapan metode IPA diawali dengan melakukan survei wawancara dengan penumpang untuk mengidentifikasi tingkat kinerja dan kepentingan berdasarkan persepsi penumpang kepada angkutan perkotaan. Kemudian hasil tersebut digolongkan berdasarkan atribut yang masuk kedalam kuadran kartesius. Diagram kartesius dapat terlihat seperti:

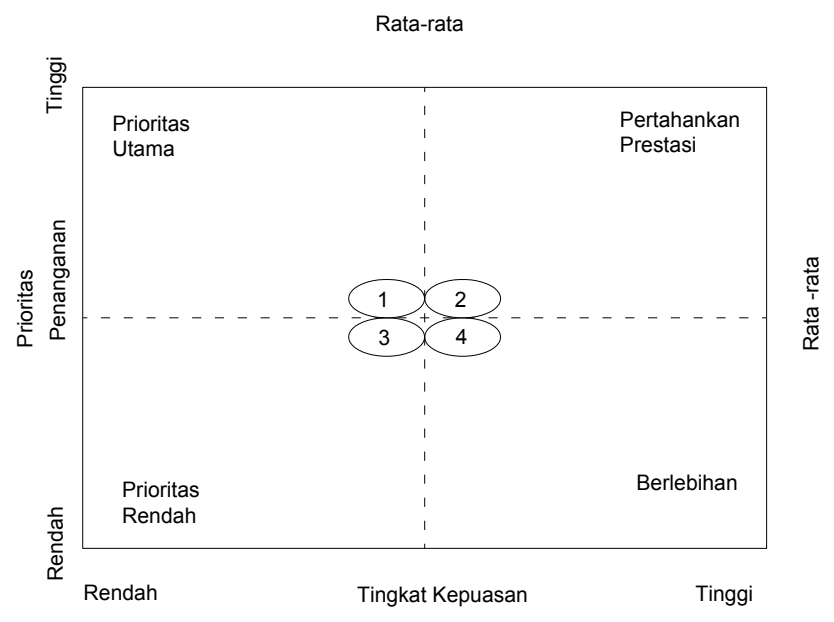

Gambar 1. Grafik Importance Performance Analysis (IPA)

Dari setiap kuadran memiliki pengertian, yaitu:

a). Kuadran 1, tingkat kepentingan tinggi namun kinerja masih belum memuaskan,

b). Kuadran 2, tingkat kepentingan sebanding dengan tingkat kepuasan,

c). Kuadran 3, pengguna menganggap tidak terlalu penting namun perlaksanaannya rendah,

d). Kuadran 4, pengguna menganggap tidak terlalu penting namun perlaksanaannya baik sekali.

Rumus yang digunakan adalah:

$$
T_{k i}=\frac{X_{i}}{Y_{i}} \times 100 \%
$$

Keterangan :

Tki $=$ Tingkat kesesuaian responden

$\mathrm{Xi} \quad=$ Skor penilaian kinerja/kepuasan

$\mathrm{Yi}=$ Skor penilaian kepentingan

* Corresponding author. Tel.: +62

E-mail address: muhisran@yahoo.com 


\section{Metodologi}

Pada skripsi ini menggunakan penelitian dengan metode Important Peformance Analysis (IPA), faktor muat (Load Factor), dan Break Even Point (BEP). Metode IPA digunakan untuk mengetahui kinerja pelayanan angkutan kota Malang dengan cara menyebar kuisioner pada para penumpang. Metode load factor digunakan untuk mengetahui faktor muat rata - rata angkutan kota Malang untuk kemudian dihitung jumlah armada berdasarkan metode Load Factor. Metode Break Even Point digunakan untuk mengetahui jumlah armada yang ideal berdasarkan pendapatan harian dan biaya operasional kendaraan harian. Kemudian jumlah armada yang dihasilkan dari metode Load Factor dan Break Even Point dibandingkan untuk mendapatkan jumlah armada yang ideal. Diagram alir kajian dapat dijelaskan pada Gambar 2.
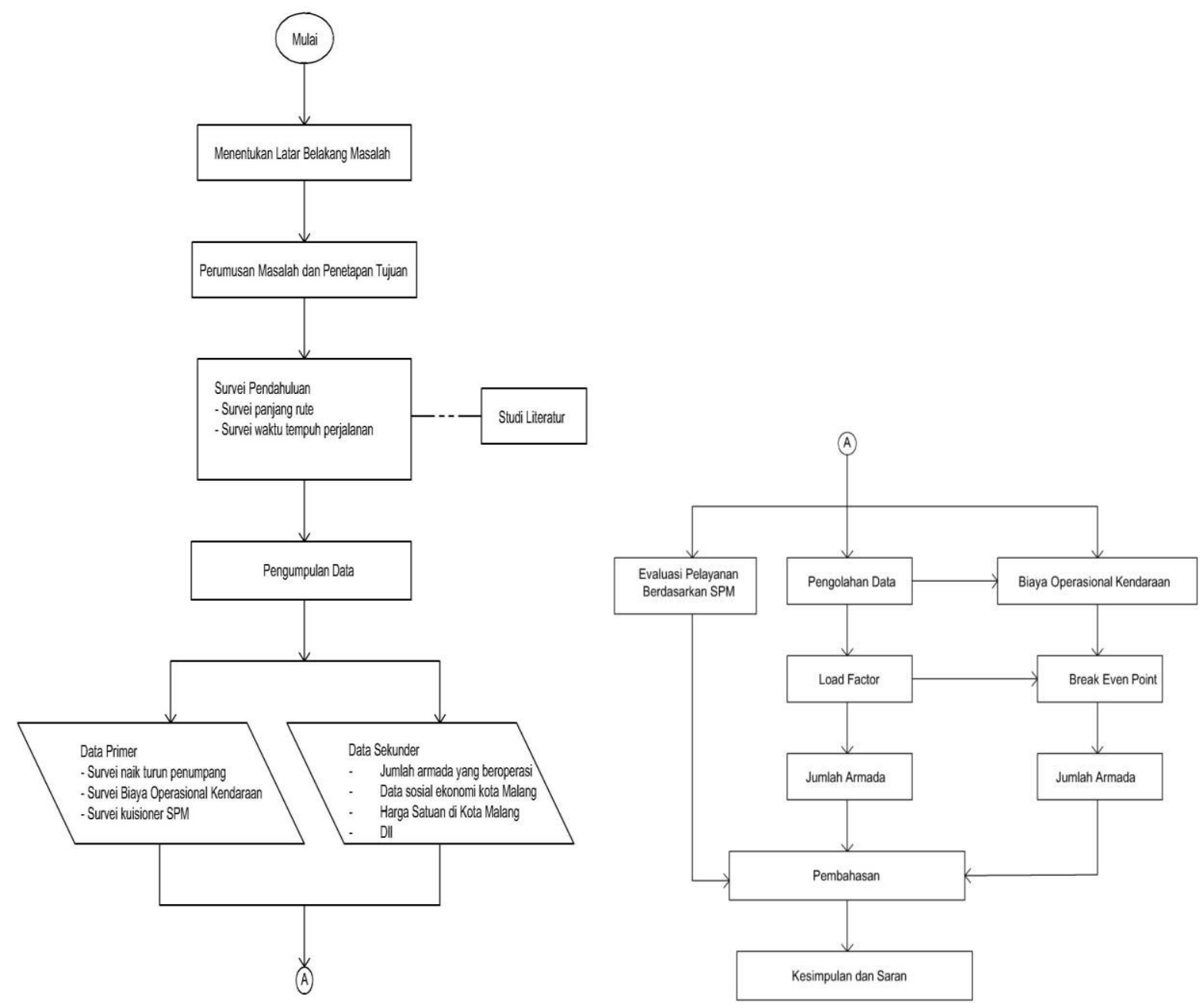

Gambar 2. Diagram Alir Kajian

\subsection{Metode Pengumpulan Data}

Data yang dibutuhkan dalam kajian ini berupa data primer yang terdiri dari survei naik turun penumpang, survei BOK, dan survei SPM. Survei naik turun penumpang dilakukan dengan mencatat jumlah penumpang angkutan kota Malang rute AH, LDH , dan ADL dari terminal awal ke terminal tujuan secara bolak bali pada jam puncak pagi (morning peak), jam tidak puncak (off peak), dan jam puncak sore (evening peak). Survei BOK dilakukan di lapangan dengan cara mewawancarai sopir angkutan kota Malang trayek AH, LDH, dan ADL. Sedangkan survei SPM dilakukan di lapangan dengan cara menyebar kuisioner pada parapenumpang angkutan kota Malang rute AH, LDH, dan ADL.

* Corresponding author. Tel.: +62

E-mail address: muhisran@yahoo.com 


\subsection{Metode Analisis}

Metode Important Performance Analysis (IPA)

Metode ini digunakan untuk mengetahui penyebaran kuadran aspek - aspek berdasarkan SPM 2015. Dari penyebaran kuadran tersebut dapat diketahui kinerja pelayanan tiap aspek yang ditinjau dari angkutan kota Malang rute AH, LDH, dan ADL. Data SPM didapatkan dari hasil kuisioner yang disebar pada para penumpang angkutan kota Malang rute AH, LDH, dan ADL.

\section{Metode Load Factor}

Metode ini digunakan untuk mengetahui faktor muat rata - rata dari armada angkutan kota Malang rute $\mathrm{AH}$, LDH, dan ADL. Data yang digunakan berdasarkan hasil survei naik turun penumpang. Hasil perhitungan Load Factor selanjutnya diolah untuk mendapatkan jumlah armada angkutan kota Malang rute AH, LDH, dan ADL.

\section{Metode Break Even Point}

Metode ini digunakan untuk menghitung jumlah armada angkutan kota Malang rute AH, LDH, dan ADL. Perhitungan ini didasarkan pada perhitungan Load Factor dan hasil survei BOK. Data BOK didapatkan dari hasil wawancara langsung sopir angkutan kota Malang rute $\mathrm{AH}, \mathrm{LDH}$, dan ADL.

\section{Hasil dan Pembahasan}

\subsection{Hasil Analisis Metode Importance Performance Analysis}

Dari hasil survei kuisioner yang dilakukan didapatkan lalu di anaisis menggunakan metode IPA. Metode IPA dibagi menjadi dua, berdasarkan kepentingan dan kinerja/ kepuasan penumpang. Tingkat kepentingan penumpang merupakaan data yang dibutuhkan dari persepsi masyarakat mengenai kepentingan beberapa aspek dalam angkutan. Tingkat kinerja/ kepuasan merupakan data yang diperoleh dari persepsi masyarakat mengenai pelayanan dari angkutan. Dari tingkat kepentingan dan kinerja/ kepuasan tersebut dicari tingkat kesesuaian untuk tiap tiap kategori.

Ada empat kategori yaitu kemanan, keselamatan, kenyamanan dan keteraturan. Kategori - kategori tersebut didasarkan pada Standart Pelayanan Minimum tahun 2015. Dari keempat kategori tersebut akan dicari rata - rata dari nilai kepuasan dan kepentingan sehingga didapatkan diagram kartesius.

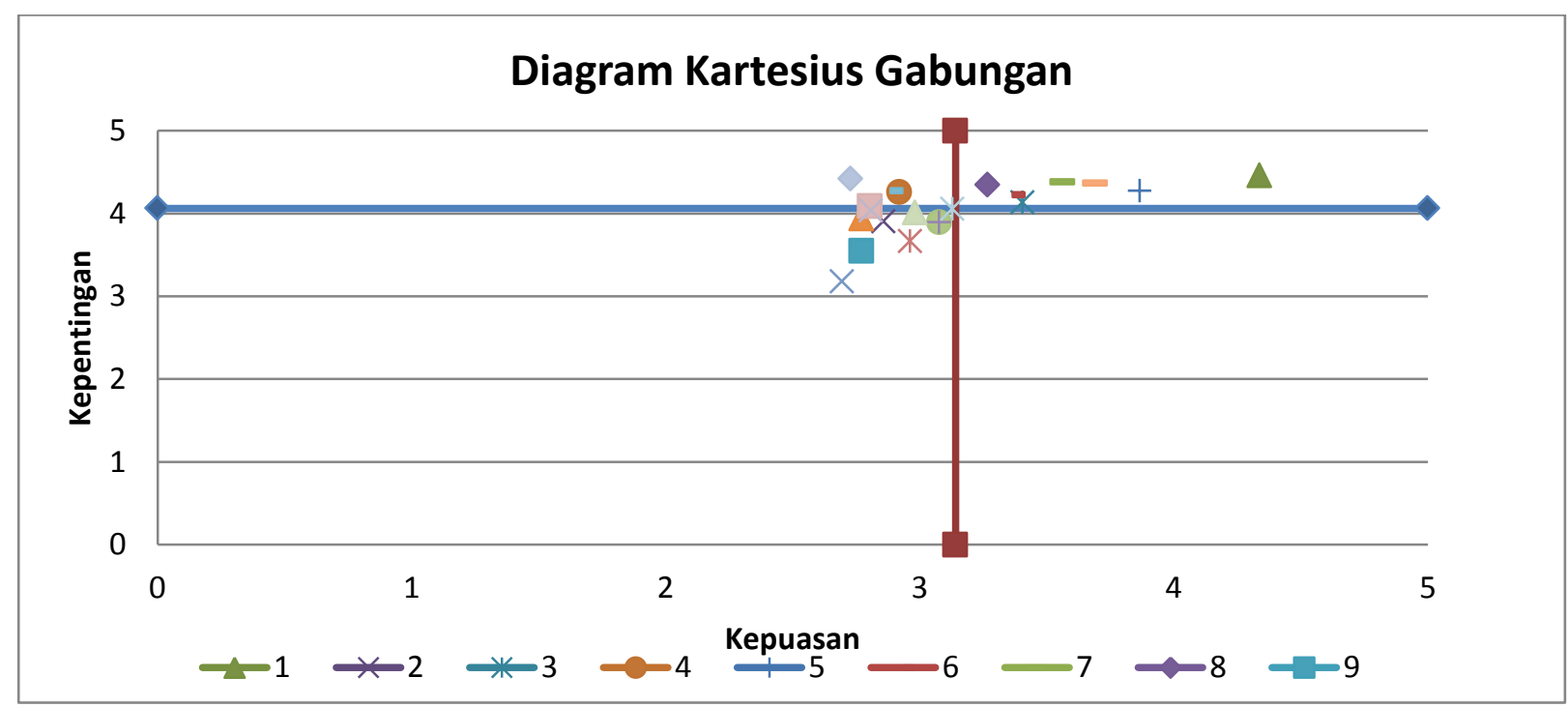

Gambar 3. Diagram Kartesuius

Aspek yang masuk dalam kuadran satu adalah sopir mengangkut penumpang tidak melebihi kapasitas, larangan merokok bagi penumpang dan sopir dalam kendaraan, adanya prioritas untuk penyandang cacat, manusia usia lanjut, anak - anak dan ibu hamil. Adanya informasi tentang waktu kedatangan dan keberangkatan.

* Corresponding author. Tel.: +62

E-mail address: muhisran@yahoo.com 
Aspek yang masuk dalam kuadran dua adalah tanda pengenal kendaraan, kondisi lampu penerangan dan tingkat kegelapan kaca film angkutan, memindahkan penumpang ke kendaraan lain yang sejenis dalam trayek yang sama tanpa dipungut biaya tambahan jika kendaraan mogok atau rusak, angkutan kota menggunakan lajur paling kiri, dan mematuhui batas kecepatan, kondisi sopir, sopir mematuhi peraturan.

Aspek yang termasuk dalam kuadran tiga adalah tanda pengenal sopir, perlunya peralatan keselamatan, adanya informasi berupa stiker tentang no telp atau sms pengaduan apabila dalam keadaan darurat, pintu keluar-masuk penumpang harus tertutup pada saat kendaraan berjalan, adanya alat pembatas kecepatan, tingkat kebersihan dari angkutan, adanya fasilitas kebersihan di dalam angkutan, waktu tunggu kendaraan dan waktu antar kendaraan.

\subsection{Hasil Analisis Jumlah Armada dengan menggunakan metode Load Factor}

Hasil faktor muat (Load faktor) trayek AH rata - rata sebesar 41\%. Faktor muat (Load faktor) trayek LDH rata - rata sebesar 40\%. Dan faktor muat (Load faktor) trayek ADL rata - rata sebesar 54\%. Dari ketiga trayek tersebut faktor muat (Load Factor) di bawah standar, yaitu sebesar $70 \%$

Kebutuhan jumlah armada rata - rata untuk trayek AH setiap harinya didapatkan sebanyak 132 kendaraan. Jumlah armada yang tersedia sebesar 300 kendaraan. Jadi jumlah kendaraan AH saat ini mengalami kelebihan sebanyak 162 armada. Dengan jumlah jam operasional 18 jam, dibutuhkan minimal 3 shift armada yang beroperasi setiap harinya. Kebutuhan jumlah Armada rata - rata untuk trayek LDH setiap harinya didapatkan sebanyak 85 kendaraan. Jumlah armada yang tersedia 170 kendaraan. Jadi jumlah kendaraan LDH saat ini mengalami kelebihan jumlah armada sebanyak 85 armada. Dengan jumlah jam operasional trayek LDH 15 jam maka dibutuhkan minimal 2 shift armada yang beroperasi setiap harinya. Kebutuhan jumlah Armada rata - rata untuk trayek ADL setiap harinya didapatkan sebanyak 75 kendaraan. Jumlah armada yang tersedia 124 kendaraan. Jadi jumlah kendaraan ADL saat ini mengalami kelebihan jumlah armada sebanyak 49 armada. Dengan jumlah jam operasional trayek ADL 15 jam maka dibutuhkan minimal 2 shift armada yang beroperasi setiap harinya.

\subsection{Hasil Analisis Jumlah Armada dengan menggunakan metode Break Even Point}

Biaya operasional kendaraan trayek AH sebasar Rp. 1.644,82/mobil-km. Angkutan kota Malang rute AH menempuh jarak rata - rata 115,36 kilometer per hari. Sehingga biaya operasional kendaraan untuk satu armada angkutan kota Malang rute AH dalam satu hari sebesar Rp. 189.745,00. Biaya operasional kendaraan trayek LDH sebasar Rp. 1.668,51/mobil-km. Angkutan kota Malang rute LDH menempuh jarak rata - rata 125,25 kilometer per hari. Sehingga biaya operasional kendaraan untuk satu armada angkutan kota Malang rute LDH dalam satu hari sebesar Rp. 208.907,90. Biaya operasional kendaraan trayek ADL sebasar Rp. 1.574,80/mobil-km. Angkutan kota Malang rute ADL menempuh jarak rata - rata 119,48 kilometer per hari. Sehingga biaya operasional kendaraan untuk satu armada angkutan kota Malang rute ADL dalam satu hari sebesar Rp. $188.156,53$.

Dari biaya operasional kendaraan dapat dihitung jumlah armada untuk tiap tiap trayek menggunakan metode break even point. Dari metode tersebut didapatkan Jumlah armada untuk trayek AH sebesar 237 kendaraan, sehingga mengalami kelebihan 63 kendaraan. Jumlah armada untuk trayek LDH sebesar 130 kendaran, sehingga mengalami kelebihan 40 kendaraan. Jumlah armada untuk trayek ADL sebesar 105 kendaran, sehingga mengalami kelebihan 19 kendaraan.

\subsection{Pembahasan}

Dari kedua metode tersebut, maka jumlah armada dapat dibandingkan dan di dapatkan jumlah armada yang ideal.

Tabel 1. Perbandingan Jumlah Armada

\begin{tabular}{|c|c|c|c|c|}
\hline \multirow[b]{2}{*}{ Trayek } & \multirow{2}{*}{$\begin{array}{l}\text { Kondisi } \\
\text { Eksisting }\end{array}$} & \multicolumn{2}{|c|}{ Metode } & \multirow{2}{*}{$\begin{array}{c}\text { Jumlah } \\
\text { Armada } \\
\text { Ideal }\end{array}$} \\
\hline & & $\begin{array}{l}\text { Load } \\
\text { Factor }\end{array}$ & $\begin{array}{c}\text { Break Even } \\
\text { Point }\end{array}$ & \\
\hline $\mathrm{AH}$ & 300 & 132 & 237 & 132 \\
\hline LDH & 170 & 85 & 130 & 85 \\
\hline ADL & 124 & 75 & 105 & 75 \\
\hline
\end{tabular}

\footnotetext{
* Corresponding author. Tel.: +62

E-mail address: muhisran@yahoo.com
} 
Dari kedua metode tersebut yang paling optimum digunakan adalah metode load factor. Karena metode tersebut didasarkan pada kebutuhan penumpang saat ini dan di analisis agar bisa mencapai standar load factor pada tiap tiap jamnya. Dan jika dilihat dari keuntungan jumlah armada tersebut masih mampu mendapatkan keuntungan.

Berdasarkan analisis jumlah armada yang ada masih melebihi kebutuhan, maka perlu dilakukan optimasi. optimalisasi dilakukan dengan cara pemangkasan jumlah armada dan peningkatan pelayanan untuk memenuhi kebutuhan penumpang. Namun apabila penerapan pemangkasan jumlah armada dan peningkatan pelayanan sulit diterapkan, optimalisasi jumlah armada yang ada untuk angkutan kota Malang dapat menggunakan cara membagi kerja jumlah armada dengan beberapa shift kerja. Seperti contoh trayek AH dengan asumsi 18 jam kerja didaptkan dari perhitungan 3 shift. Setiap shift mendapatkan 6 jam kerja. Jika rata - rata setiap harinya membutuhkan 300 armada maka setiap shiftnya akan membutuhkan 100 jumlah armada. Jumlah tersebut masih dibawah jumlah yang dibutuhkan menurut metode Load Factor sebesar 132, sehingga cara tersebut dapat diterapkan bersamaan dengan peningkatan pelayanan.

\section{Penutup}

\subsection{Kesimpulan}

1. Pelayanan angkutan kota Malang trayek AH, LDH, dan ADL berdasarkan Standart Pelayanan Minimum (SPM) tahun 2015 di dapatkan ada beberapa aspek yang berada di prioritas utama dan kinerja pelayanan angkutan umum yang rendah. Aspek yang berada pada prioritas utama tersebut adalah sopir mengangkut penumpang tidak melebihi kapasitas, larangan merokok bagi penumpang dan sopir dalam kendaraan, adanya prioritas untuk penyandang cacat, manusia usia lanjut, anak - anak dan ibu hamil. Adanya informasi tentang waktu kedatangan dan keberangkatan.

2. jumlah armada yang tersedia untuk trayek AH, LDH, dan ADL melebihi kebutuhan yang ada apabila di analisis dengan menggunakan metode Load Factor dan metode Break Even Point.

3. Yang lebih efisien dari penentuan jumlah armada diantara metode Load Factor dan Break Even Point adalah dengan Load Factor. Karena metode tersebut didasarkan pada rata - rata jumlah penumpang yang ada, jadi jumlah armada yang di dapatkan akan sangat efisien. Berbeda dengan metode Break Even Point yang perhitungannya di dasarkan dari jumlah pengeluaran dan pemasukan dari angkutan umum. Jadi banyak jumlah armada yang di dapatkan dari berapa banyak jumlah keuntungan yang diinginkan.

4. Pada kondisi ideal, optimasi jumlah armada dapat dilakukan dengan cara pemangkasan jumlah armada dan peningkatan pelayanan. Namun apabila penerapan pemangkasan jumlah armada dan peningkatan pelayanan sulit diterapkan, optimalisasi jumlah armada yang ada untuk angkutan kota Malang dapat menggunakan cara membagi kerja jumlah armada dengan beberapa shift kerja.

\subsection{Saran}

1. Untuk pengkaji selanjutnya dalam pembagian kuisioner pelayanan sebaiknya lebih selektif saat pemilihan responden supaya data yang diperoleh lebih merata, sehingga bisa mengetahui berapa besar potensi penumpang yang terjadi.

2. Untuk pengkaji selanjutnya agar dapat membuat rekayasa pembagian shift armada yang beroperasi dalam rangka optimalisasi sehingga dapat mengetahui perbedaan hasil kajian dalam keadaan sesungguhnya dengan keadaan yang telah dioptimalisasi.

3. Untuk pemerintah dalam hal ini Dinas Perhubungan Kota Malang dapat bekerja sama dengan paguyuban angkutan Kota Malang dalam hal pembenahan sistem angkutan Kota Malang agar angkutan Kota Malang diminati oleh warga kota Malang.

\section{DAFTAR PUSTAKA}

\section{Use the "Insert Citation" button to add citations to this document.}

[1] Agung, Marga Rista, dan Rizqian, Mufidz Akbar, 2016. Kajian Penentuan Tarif Angkutan Kota di Kota Malang (Studi Kasus Angkutan Kota Trayek AG dan TST) Tugas Akhir. Malang: Universitas Brawijaya.

\footnotetext{
* Corresponding author. Tel.: +62

E-mail address: muhisran@yahoo.com
} 
[2] Biaya Operasi Kendaran. Tersedia pada: https://hmtsunsoed.files.wordpress.com/2012 /04/1-bab-1-biaya-operasikendaraan-dr-gito sugiyanto.pdf [diakses tanggal 5 Februari 2016]

[3] Direktorat Jendral Perhubungan Darat, 2002. Pedoman Teknik Penyelenggaraan Angkutan Umum di Wilayah Perkotaan dalam Trayek Tetap dan Teratur. Jakarta: Departemen Perhubungan RI.

[4] Direktorat Jendral Perhubungan Darat, 2013. Peraturan Menteri Republik Indonesia Nomer PM 98 Tahun 2013. Jakarta: Departemen Perhubungan RI.

[5] Direktorat Jendral Perhubungan Darat, 2015. Peraturan Menteri Republik Indonesia Nomer PM 29 Tahun 2015. Jakarta: Departemen Perhubungan RI.

[6] Fahmi, Ahmad dan Pradhana, Bintang., 2015. Kajian Kinerja Operasional Angkutan Umum Pada Trayek Malang Lumajang. Tugas Akhir. Malang: Universitas Brawijaya.

[7] Jalur Angkutan Kota Malang. Tersedia pada: http://mediacenter.malangkota.go.id/info-kota/transportasi/jalurangkutan-kota-malang/\#ixzz3yxx82CKC[diakses tanggal 2 Februari 2016].

[8] Khisty, C. Jotin, dan Lall, B. Kent, 2006. Dasar-Dasar Rekayasa Transportasi Jilid 2. Jakarta: Penerbit Erlangga.

[9] Pemerintah Republik Indonesia, 1993. Peraturan Pemerintah Republik Indonesia Nomer 41 Tahun 1993. Jakarta: Pemerintah RI.

[10] Setiawati, Dewi.,Aviasti.,Rukmana, Asep Nana. 2015. Penetuan Jumlah Armada dan Rute Angkutan Kota yang Optimal di Kota Bandung Berdasarkan Load Factor (Studi Kasus: Trayek Riung Bandung - Dago). Tersedia di karyailmiah.unisba.ac.id/index.php/industri/article/download/436/pdf[Diakses tanggal 22 Januari 2016]

[11] Sholichin, Ibnu, dan Herijanto, Wahyu, 2008. Evaluasi Penyedia Angkutan Penumpang Umum dengan Menggunakan Metode Berdasarkan Segmen Terpadat Rata-Rata Faktor Muat dan Break Even Point (Studi Kasus: Trayek Terminal Taman Terminal Sukodono). Tersedia http://digilib.its.ac.id/evaluasi-penyediaan-angkutan-penumpang-umum-denganmenggunakan-metode-berdasarkan-segmen-terpadat-ratarata-faktor-muat-dan-break-even-point-studi-kasus-trayekterminal-tamanterminal-sukodono/27097[Diakses tanggal 22 Januari 2016]

[12] Tamir, Ofyar Z., 1997. Perencanaan dan Pemodelan Transportasi. Bandung: Penerbit ITB. 